\title{
Reforzar la prevención ante el crecimiento de casos y la amenaza de la nueva variante del SARS-CoV-2
}

\author{
Reinforce prevention to confront the rise in cases of \\ COVID-19 and the threat of new viral variants
}

\author{
José Rogelio Pérez-Padilla*
}

*Instituto Nacional de Enfermedades Respiratorias Ismael Cosío Villegas, Ciudad de México.

Palabras clave: COVID-19, pandemia, intervenciones no farmacológicas, prevención.

Keywords: COVID-19, pandemic, non-pharmacologic interventions, prevention.

En marzo y abril de 2009, al demostrarse los primeros casos de la pandemia de influenza H1N1, se declaró un cierre completo en la Ciudad de México por semanas, y como resultado el brote inicial fue muy corto. Para octubre de 2009 tuvimos un segundo brote más prolongado y violento, en buena medida por mantener la actividad económica.

Ahora con el COVID-19 podemos ver que lo económico pesa y mucho. Las presiones de las personas que viven al día, o que trabajan en lugares que se consideran de riesgo de contagio y tienen que cerrar, así como de las organizaciones patronales y empresariales, son poderosas. A pesar de las implicaciones económicas adversas, el semáforo pasó a color rojo por el crecimiento desmedido de enfermos, a mi parecer correctamente.

Estamos en enero de 2021 en un prolongado y creciente segundo brote de COVID-19 en el Valle de México y en otros sitios, con los servicios de salud saturados y con el llamado semáforo (en color rojo desde la época navideña) que ha sido incapaz de aminorar la trayectoria creciente de los casos y de las muertes, y por supuesto lo será aún más con la inminente amenaza de la llegada de una o más

Correspondencia:

Dr. José Rogelio Pérez-Padilla

Instituto Nacional de Enfermedades Respiratorias Ismael Cosío

Villegas, Ciudad de México.

Correo electrónico: perezpad@gmail.com

Recibido: 29-I-2021; Aceptado: 02-II-2021.

Citar como: Pérez-Padilla JR. Reforzar la prevención ante el crecimiento de casos y la amenaza de la nueva variante del SARS-CoV-2. Neumol Cir Torax. 2021; 80 (1): 4-5. https://dx.doi.org/10.35366/99446 variantes virales más contagiosas y agresivas. ${ }^{1}$ La pandemia de COVID-19 ha sido implacable.

Ante el ritmo del crecimiento de casos tenemos que concluir que las medidas han sido mucho más benignas que el virus circulante, y por lo mismo se ven desproporcionadamente pequeñas para una variante viral más agresiva por llegar, si no es que ya está circulando. Sin duda, la implantación de medidas más estrictas y de cumplimiento verificado requerirán de ampliar los programas de apoyo a la población y a las empresas o negocios que cierran, pero la alternativa es un mayor incremento en los fallecimientos.

Que quede claro, no es sólo un problema de México. En Europa se está considerando la necesidad de implantar medidas más severas porque las actuales son insuficientes, ${ }^{1,2}$ y de imponerlas aun a pesar de la presencia de grupos organizados que se oponen a éstas. Se ha demostrado ya una tendencia a reducir el apego a las medidas de prevención no farmacológicas, salvo al cubrebocas. ${ }^{3}$

El crecimiento constante en los infectados se ve en los datos que se presentan día a día, y el incremento de éstos implica más muertos. La vacunación no será posible con la rapidez que la emergencia requiere, ni es seguro que el uso de medicamentos a gran escala (como la ivermectina o la azitromicina, siguiendo el ejemplo de otros países en Latinoamérica) reduzca de manera significativa la mortalidad ante el nuevo virus y un número creciente de casos. ${ }^{4}$ Las muertes son el evento final y el más impactante de un brote; pero en enfermos graves, la mortalidad sigue siendo inaceptablemente alta, aun con los mejores tratamientos de beneficio comprobado disponibles. Se tiene que actuar previniendo infecciones a pesar del costo económico, ya que todas las familias con enfermos y decesos también empobrecen y su capacidad económica puede perderse en forma permanente.

Como prueba de la bondad de la prevención, del uso amplio de las llamadas «medidas de prevención no 
farmacológicas», la vida diaria en Wuhan ha regresado a la normalidad con el florecimiento inclusive de la vida económica después de medidas de aislamiento severísimas que resentían y sufrían sus propios ciudadanos. Fue importante reducir los casos hasta cero en lugar de mantenerlos en un número inferior al de las capacidades hospitalarias, y ahora más que nunca lo percibimos con la inminencia de la llegada de un virus más transmisible en un momento en el que el sistema de salud está saturado y bajo estrés.

Desde hace décadas se ha alertado de las pandemias por venir, y ni la presencia de la influenza AH1N1 en 2009 pudo mejorar las condiciones para enfrentar una crisis como la que ahora nos mata. El sistema de salud, minimizado, ha tenido que enfrentar esta emergencia, con personal escaso, con muchas bajas y con la escasez internacional de insumos que genera la pandemia activa en casi todo el mundo.

Seguimos como especie desatendiendo urgentes recomendaciones en contra de nuestra forma descontrolada e invasiva de interacción con el mundo, origen final de las pandemias y de otros riesgos que impactan de manera predominante a la población desprotegida, cada vez más numerosa.

Ningún país está preparado para un incremento rápido de infecciones como las que se esperan con las nuevas variantes virales. La prevención ha demostrado utilidad ahora y en brotes previos, y las medidas deben ser tan severas como el brote lo requiera, asegurando su cumplimiento, de preferencia fomentando el convencimiento de todos y sin duda, al mismo tiempo, mitigar en lo posible los perjuicios sociales y económicos que genere.

\section{REFERENCIAS}

1. European Center for Disease Control. Risk of spread of new SARSCOV-2 variants of concern in the EU/EEA-first update. ECDC 2021: 29. https://www.ecdc.europa.eu/sites/default/files/documents/ COVID-19-risk-related-to-spread-of-new-SARS-CoV-2-variants-EUEEA-first-update.pdf.

2. Fuller JA, Hakim A, Victory KR, Date K, Lynch M, Dahl B, et al.; CDC COVID-19 Response Team. Mitigation policies and COVID-19associated mortality-37 european countries, January 23-June 30, 2020. MMWR Morb Mortal Wkly Rep. 2021;70(2):58-62. https://doi. org/10.15585/mmwr.mm7002e4.

3. Crane MA, Shermock KM, Omer SB, Romley JA. Change in reported adherence to nonpharmaceutical interventions during the COVID-19 pandemic, April-November 2020. JAMA. 2021;e210286. https://doi. org/10.1001/jama.2021.0286.

4. Mega ER. Latin America's embrace of an unproven COVID treatment is hindering drug trials. Nature. 2020;586(7830):481-482. https://doi. org/10.1038/d41586-020-02958-2; https://www.nature.com/articles/ d41586-020-02958-2.

Conflicto de intereses: Sin conflicto de intereses. 